distortions. Nature, 1965, 207. 891-893.

Day. R. H. Visual spatial illusions: A general explanation. Science. 1972, 175, 1335-1340.

Fisher. G. H. An experimental and theoretical appraisal of the inappropriate size-depth theories of illusions. British Journal inappropriate size-depth theories
of Psychology, $1968,59,373-383$.

Gregory, R. L. Distortion of visual space as inappropriate constancy scaling. Nature, 1963, 199, 678-680.
Gregory, R. L. Seeing in depth. Nature, 1965, 207. 16-19.

Massaro, D. W.. \& Anderson. N.H. A test of perspective theor of geometrical illusions. American Journal of Psychology. $1970,83,567-575$.

(Received for publication May 29.1973.)

\title{
A comparison of presentation rates using a missing item probe test of immediate memory *:
}

\section{NANCY S. ANDERSON $\dagger$ and V. DAVID BURNS \\ Lniversity of Maryland, College Park. Md. 20742}

Two experiments are reported in which presentation rates were compared using a "missing-item" probe technique for digit lists of 12 or 16 items. The results replicate previous studies (e.g., Waugh \& Norman, 1965) in that probability of recall was found to be a monotonically decreasing function of the number of intervening items and no significant differences were found between presentation rates. The results are interpreted as further evidence against a time decay hypothesis in immediate probed recall.

Several hypotheses have been proposed to explain the result that, when memory is tested at brief delays

* This research was supported in part by a grant from the Biomedical Sciences Support Center of the University of Maryland to the Center for Language and Cognition, and the computer time was supported through the facilities of the Computer Science Center.

tRequests for reprints should be sent to Nancy $S$. Anderson, Department of Psychology. University of Maryland. College Park. Md. 20742. following presentation, more recent list items are recalled with a higher probability than earlier items (recency effect). Brown (1958) argued that an item's trace strength decays over time. whereas other investigators (e.g., Waugh \& Norman, 1965) have concluded that interference resulting from the presentation of subsequent items is the primary cause of the effect. Of course, both factors could contribute to forgetting, as has been shown by Wicklegren (1970).

One method of distinguishing among the hypotheses is to compare performance across presentation rates. Unfortunately this comparison is complicated by the presence of differential time for rehearsal or encoding across presentation rates and by the possibility that order of recall interacts with presentation rate differences (Posner, 1964). The latter difficulty can be avoided by requiring the recall of only a single item within each list, e.g., by presenting a single-item probe and instructing Ss to recall the item which followed it in the original list (Waugh \& Norman. 1965). Waugh and Norman also instructed their Ss not to rehearse previous 


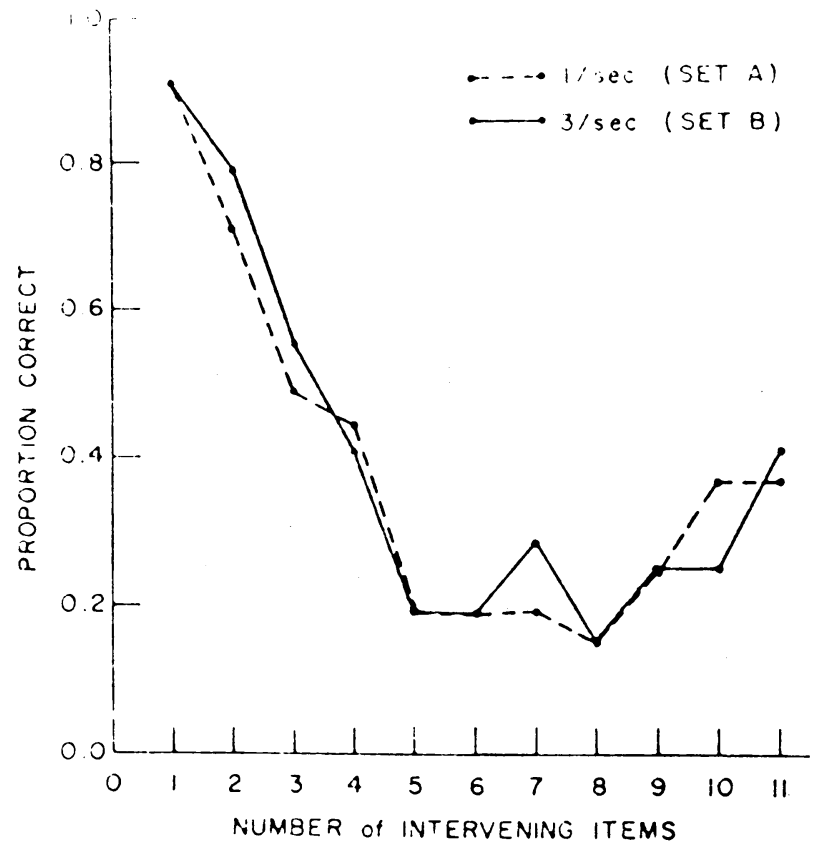

Fig. 1. Proportion correct as a function of number of intervening items for each rate of presentation for lists of 12 digits.

items, thus controlling for one possible source of differential encoding across presentation rates. Their results indicated that probability of recall (corrected for guessing) was a monotonically decreasing function of the number of items intervening between presentation of a item and test for that item, and that there were no significant differences between presentation rates. Hence, they concluded that the main source of forgetting was due to interference. The same conclusion was reached by Norman (1966) for several presentation rates and both auditory and visual modes using the single-item probe.

\section{EXPERIMENT I}

The purpose of the first experiment was to compare performance at two presentation rates similar to those used by Waugh and Norman but to use a "missing-item" probe technique for shorter list lengths. In the "missing-item" probe technique. the entire list except for a single to-be-recalled item is presented at time of test. Since the maximum amount of information is made available to $S$ as a cue for recall of the critical item. the "missing-item" task may provide a more sensitive measure of memory for the tested item.

\section{Method}

Lists of 12 random digits were recorded on tape at rates of either 1 or $3 / \mathrm{sec}$. Ss were tested in groups of 8 or 10 during a 20-min interval. which served as the intervening task during a serial learning and retention experiment reported by Anderson (1969). Ss listened to a tape-recorded presentation of 12 digits at either 1 or $3 / \mathrm{sec}$. After each list. the E held up a card with 11 of the 12 digits on it. with an underlined blank space indicating the mising digit. and S, were instructed to write down the digit that occurred at that position in the original list. guessing if uncertain. In contrast to Waugh and Norman. who did not probe the first or last two strial positions. or selected other positions in the middle of the list, all 12 positions were probed in this study. Sixty-eight Ss were tested at the slow rate. and 76 Ss were tested at the fast rate. The first five trials in each session were considered practice and were not scored. Again. Ss were asked not to rehearse previous items.

\section{Results and Discussion}

Proportion of correct responses, transformed by the linear correction for guessing (with $\mathrm{g}=.1$ ) used by Waugh \& Norman (1965), is shown in Fig. 1 for each rate of presentation as a function of number of intervening items. The data are similar to those found by Waugh \& Norman (1965) in that proportion correct was a decreasing function of the number of intervening items, and no differences were found between rates of presentation. These data differ only in that a slight primacy effect was found for the first and second items. The primacy effect can be accounted for by either the slightly slower rate of $3 / \mathrm{sec}$ compared to $4 / \mathrm{sec}$ used by Waugh and Norman and/or by the fact that all positions, including the first two, were probed in the present study compared to that of Waugh and Norman. Alternatively, some Ss may have been rehearsing, even though the instructions asked them not to rehearse.

\section{EXPERIMENT II}

The purpose of the second experiment was to test further the time decay vs interference hypotheses with the "missing-item" probe and additional controls for differential encoding. Confidence ratings were also obtained in order to estimate sensitivity, using memory operating characteristics (MOCs).

\section{Procedure \\ Method}

Thirty-six University of Maryland undergraduates volunteered as Ss and were given course credit for their participation. The stimuli consisted of 16-digit lists and were displayed, 4 digits per exposure, in a Scientific Prototype tachistoscope set for either $1 \mathrm{sec} /$ exposure (for the 4-digit/sec presentation rate) or $4 \mathrm{sec} /$ exposure (for the $1 \mathrm{digit} / \mathrm{sec}$ rate). Ss were instructed to read each digit aloud in time with a metronome set at the appropriate rate and not to rehearse previous items. In addition, half of the Ss also voiced the word "the" aloud after each digit read at the slow rate. The word "the" was chosen to fill the interval between digits in an attempt to reduce subvocal articulation of items, as suggested by Murray (1968).

Prior to each list. $\mathrm{S}$ focused on a fixation point and then pressed a button, which after a $1 / 2-\sec$ delay initiated presentation of a list. Following the last exposure. a dark field signaled $S$ that he was to turn the page in his answer booklet and fill in the missing digit. guessing if he did not know. The item to be recalled was indicated by a blank space (underlined) at the appropriate position. After writing his digit response. $S$ was instructed to indicate with one of the letters a. b. c. or d the degree of confidence in his response. Each S was exposed to 188 lists in a session lasting about $75 \mathrm{~min}$.

\section{Design}

Lists of 16 digits were constructed. using all 10 digits ( 0 to 9). subject only to the restriction that no item occur more than 
three times per list. Hence. in the "missing-item" as opposed to the single-item probe technique. the digit preceding the critical digit can occur elsewhere in the list. Only Serial Positions 2. 3.4. 6. 8. 10.11. 12. 14. and 15 were probed. and each of these was probed equally often in a pseudorandom sequence. Sessions were divided into four blocks. two at each presentation rate. and the orders of presentation rates were counterbalanced. The first four lists at each presentation rate were practice trials and were not scored.

\section{Results}

The proportion of correct responses (corrected for guessing) as a function of number of interfering items is shown in Fig. 2. Probability of a correct response decreased monotonically with number of intervening items, and no significant differences were obtained between presentation rates. Serial position differences were significant $(F=147.1: \mathrm{df}=9.270: \mathrm{p}<.01)$. but there were no significant differences between the filled (saying "the") and unfilled intervals or between orders of presentation rates.

An unexpected result was a superiority at the slow presentation rate by Ss who voiced "the" between digits, whereas at the fast rate Ss who never voiced "the" between items at the slow rate showed better performance (Table 1). The effect, though small, was reflected in the interaction of presentation rate with the filled or unfilled interdigit interval $(F=3.6: \mathrm{df}=1,30: \mathrm{p}$ $=.07$ ).

Estimates of sensitivity were calculated by first combining proportion correct across Ss, separated according to confidence ratings. presentation rate. serial position, and filled-unfilled interval, in order to generate memory operating characteristic (MOC) functions. The $A_{g}$ measure (suggested by Green \& Swets. 1966, and Banks, 1970). representing the area under the MOC function, was computed for each rate (averaged over the filled and unfilled interval conditions) at each serial

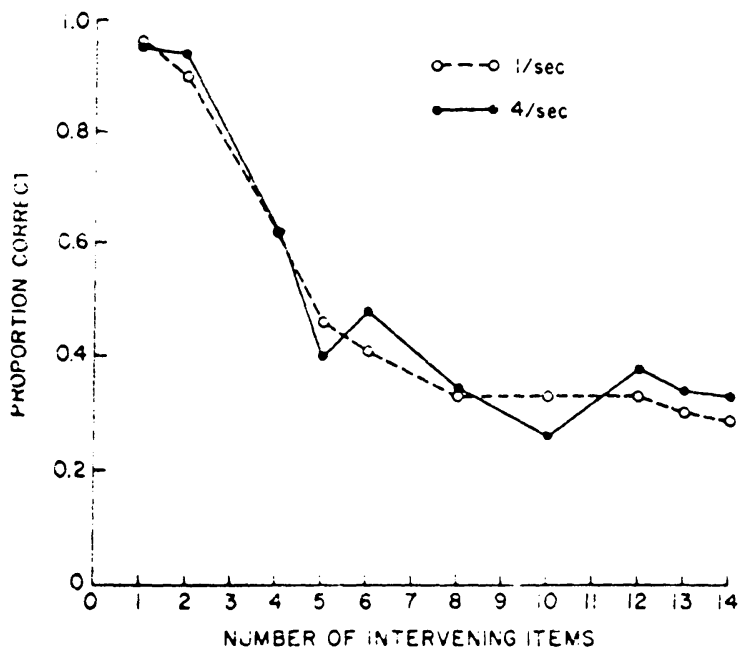

Fig. 2. Proportion correct as a function of number of intervening items for each rate of presentation for lists of 16 digits.
Table 1

Average Proportion Correct

\begin{tabular}{ccc} 
Group & Rate of Presentation \\
\cline { 2 - 3 } & Onc Per & Four Per \\
Silled (the) & .51 & Sciond \\
Cinfilled & .49 & .48 \\
\hline
\end{tabular}

position tested. The sensitivity $\left(\mathbf{A}_{\mathbf{g}}\right)$ measure for the ? presentation rates and 10 serial positions tested showed superior performance at the slow presentation rate for 7 of 10 serial positions. A recency effect was evident using the sensitivity measure similar to that found with proportion correct. No consistent differences between the filled and unfilled interval conditions were found using the $A_{\mathbf{g}}$ measure.

\section{DISCUSSION}

The results of both experiments replicate previous studies (Waugh \& Norman. 1965: Norman. 1966) in that no evidence for differential forgetting rates between presentation rates or a superiority of performance at the fast presentation rate was obtained. The present study extends the previous results to the missing-item probe procedure. to a 12 -item list, and to the case when another possible confounding factor, that of encoding. is controlled. and hence provides further evidence against the hypothesis of time decay in the immediate probe recall task. The unexpected superiority of performance at the slow presentation rate by $S s$ in the filled-interval condition in Experiment II argues against the presence of rehearsal and suggests that saying "the" in the interdigit interval may actually facilitate performance. perhaps by increasing the discriminability among items.

In summary, the results of the present studies. in which presentation rates were compared using a missing-item probe and both an encoding and rehearsal control. replicate and extend previous results by Waugh \& Norman (1965) in that no evidence for a decay of trace strength over time was obtained. Probability of recall was found to be a monotonically decreasing function of number of intervening items. and no significant differences between presentation rates were found: hence, the interference account of the recency effect was supported. The fact that sensitivity estimates were generally superior at the slow presentation rate most likely reflects the advantage of perceptual grouping or other acquisition processes.

\section{REFERENCES}

Anderson, N. S. The influence of acoustic similarity on serial recall of letter sequences. Quarterly Journal of Experimental Psychology, 1969, 21, 248-255.

Banks, W. P. Signal detection theory and human memory. Psychological Bulletin, 1970, 74, 81-99.

Brown, J. Some tests of the decay theory of immediate memory. Quarterly Journal of Experimental Psychology, 1958, 10. 12-21

Green, D. M., \& Swets, J. A. Signal detection and psychophysics. New York: Wiley, 1966.

Murray, D. J. The role of speech responses in short-term memory. Canadian Journal of Psychology, 1967, 21, 263-275. Norman, D. A. Acquisition and retention in short-term memory. Journal of Experimental Psychology, 1966, 72, 369-381.

Posner, M. I. Rate of presentation and order of recall in immediate memory. British Journal of Psychology, 1964,55. 303-306.

Waugh, N. C., \& Norman, D. A. Primary memory. Psychological Review, 1965, 72,89-105

Wicklegren, W. A. Time, interference, and rate of presentation in short-term recognition memory. Journal of Mathematical Psychology, 1970,7,219-235.

(Received for publication June 27. 1973.) 